\title{
Robin N. Kamal, Arnold-Peter Weiss: Comprehensive board review in orthopaedic
}

\section{Thieme 2016; softcover; 560 pp; 89,65 €: ISBN: 978-1-60406-904-4}

\author{
Pierre Kehr $^{1}$ - Alain G. Graftiaux ${ }^{1}$
}

Received: 15 May 2017/ Accepted: 30 May 2017/Published online: 13 June 2017

(C) Springer-Verlag France SAS 2017

The goal of this book is to prepare the students for the examinations: "orthopaedics in training examination" and "American board of orthopedic surgery." This book will be also useful for the older surgeons for their re-certification. This book takes again fundamental orthopedic surgery. The various chapters show at the same time the various articulations (hip, knees, shoulder, hand...) but also of the more specific subjects like pediatry, the medicine of the sport, the amputations and rehabilitation or biomechanics and the statistics.
A book to revise its basic more particularly intended for North America.

Alain G. Graftiaux

Strasbourg

France

Compliance with ethical standards

Conflict of interest The authors declare that they have no competing interests.

Pierre Kehr

pierre.kehr@gmail.com

1 Strasbourg, France 